\title{
GENETIC PERFORMANCE OF THE STRIPED CATFISH (Pangasianodon hypophthalmus Sauvage, 1878) POPULATION DERIVED FROM SELECTIVE BREEDING
}

\author{
Huria Marnis\#, Evi Tahapari, and Jadmiko Darmawan \\ Research Institute for Fish Breeding \\ Jl. Raya 2 Pantura Sukamandi, Patokbeusi, Subang, West Java, Indonesia
}

(Received 16 March 2018; Final revised 2714 May 2018; Accepted 15 May 2018)

\begin{abstract}
Selective breeding to improve growth trait in striped catfish (Pangasianodon hypophthalmus) need genetic performance data. This study was carried out to evaluate genetic performance of different generations of the striped catfish population derived from selective breeding. Fifty fish of each population from four generations selected striped catfish was analyzed using five microsatellite loci (Pg-1, Pg-2, Pg-3, Pg-13, and Pg-14). Microsatellite allele data were analyzed using Microsoft Excel, Arlequin, and $F_{\text {stat }}$ software. A neighborhood joining dendrogram was constructed based on Nei's distance (Da) matrix with 1,000 bootstrap replications using MEGA7 software. The result showed that totally 31.5 exist, ranged from 4-7. Number of allele was ranged from 5.0 to 5.2 , and polymorphic data was from $0.45-0.60$. There were some exception, such as the allele of the loci Pg-2-194 bp, Pg-13-227 bp, Pg-13-229 bp, and Pg-14-279 bp; their gene frequencies were increased by generation. Further analyses indi-cated that most genetic variations arise from individuals within populations (approximately $57.10 \%$. The founder generation closely related to G-0 generation. Likewise, G-1 generation closely related to G-2 generation. This result indicated that selection activity had a very significant impact on the genetic improvement of the selected population.
\end{abstract}

KEYWORDS: genetic structure; microsatellite; selective breeding; Pangasianodon hypophthalmus

\section{INTRODUCTION}

Freshwater fish contributed a high proportion $84 \%$ from total production of aquaculture (Gjedrem et al., 2012). One species Pangasianodon hypophthalmus, of freshwater fish, contributes to increasing the aquaculture production. Recently, genetic of this species has been improving continually for intensifying its production through breeding program. In supporting to a breeding program, information regarding genetic variability, and structure is required.

Nowadays, several of molecular markers, based on variable polymerase chain reaction (PCR) can provide a rapid and affordable approach for collecting polymorphism data on a genomic scale (Campbell et al., 2003; Luikart et al., 2003). Nevertheless, microsatellites or simple sequence repeats (SSRs) has been applied to evaluate the genetic variability and relationships among aquaculture stock. It has been

\footnotetext{
\# Correspondence: Research Institute for Fish Breeding.

II. Raya 2 Pantura Sukamandi, Patokbeusi, Subang,

West Java, Indonesia

Phone: + 62260520500

E-mail: marnis.huria@gmail.com
}

useful for the characterization of genetic stocks, broodstock selection and mapping economically important quantitative traits, especially in aquaculture (Chistiakov et al., 2006). Moreover, microsatellites have enormous potential to improve the efficiency and precision of conventional fish breeding via markerassisted selection (MAS) (Sun et al., 2015).

Number of studies have been using microsatellite markers to conduct genetic monitoring in selective breeding lines, such as Siniperca scherzeri (Luo et al., 2015), Ruditapes philippinarum (Yu et al., 2011), and Pseudosciaena crocea (Hao et al., 2010). Nevertheless, few information about genetic structure of striped catfish populations thought breeding program. The aim of this study was evaluated genetic structure of the striped catfish (Pangasianodon hypophthalmus) population through selective breeding.

\section{MATERIALS AND METHODS}

\section{Fish and DNA Sample}

In 2010, a selective breeding program using family selection for growth traits was established in Research Institute for Fish Breeding (RIF) Sukamandi, 
Ministry of Marine Affairs and Fisheries Republic of Indonesia. A total number of broodstock were 84 individual which gathered from the collection of RIF. It was 49 sires and 35 dams. Selection for fast growth was held by selected only $10 \%$ for producing next generation.

\section{DNA Extraction}

The fin chips of 50 samples were randomly selected from each generation for genetic analysis and dipped in $70 \%$ ethanol. Total genomic was extracted from fin clips using DNA extraction kit (Genejet Genomic DNA Purification) following the protocols recommended by the manufacturer (Thermo Scientific, Lithuania). The genome sample was run on mini horizontal gel electrophoresis. The sample was loaded into the $1.5 \%(\mathrm{w} / \mathrm{v})$ agarose gel, powered with 65 -volt electricity and run for 60 minutes. The gel was then stained with peqGREEN (Vwr, UK) $1 \mu \mathrm{g} / \mathrm{mL}$ and viewed using gel documentation system ultraviolet Trans illuminator.

\section{Microsatellite Primers}

Five microsatellite loci Pg-1, Pg-2, Pg-3, Pg-12, and Pg-14 were used in this study (Na-Nakorn et al., 2006; Na-Nakorn \& Moeikum, 2009). It showed that polymorphisms microsatellites loci in Pangasianodon hypophthalmus. The primers characteristics used to amplify the five microsatellite loci are presented in Table 1.

\section{Amplification of Microsatellite Locations and Scoring}

At amount $2 \mu \mathrm{L}(\leq 200 \mathrm{ng})$ extracted genomic DNA was amplified using type-it microsatellite PCR
(Qiagen). The PCR process was carried out by the program: $95^{\circ} \mathrm{C}$ for five minutes; $\left(95^{\circ} \mathrm{C}\right.$ for 30 seconds, $6^{\circ} \mathrm{C}-62^{\circ} \mathrm{C}$ for 90 seconds according to the degree of attaching temperature (Tm) per primer (Table 1 ); $72^{\circ} \mathrm{C}$ for 30 seconds) of 28 cycles; and $72^{\circ} \mathrm{C}$ for $30 \mathrm{~min}$ utes. The PCR amplification results were loaded on $2 \%(\mathrm{w} / \mathrm{v})$ agarose gel by an electrophoresis method. The electrophoresis results observed under UV Transilluminator and photographed using a Canon EOS 1100D digital camera.

Microsatellite locus polymorphisms were screened using the QIAxcel (Qiagen) fragment analyzer and using QIAxcel DNA High resolution (Qiagen) kit, and the size of the alleles was determined based on PCR product size relative to the size of the DNA fragment on QX size marker 50-800 bp (Qiagen) and alignment marker 50-1,000 bp (Qiagen). Patterns of DNA band and electrophoregram data were analyzed using QIAxcel screen Gel software 1.5 (Qiagen) to scan alleles that emerged. The allele score data were used for the analysis of relevant genetic parameters.

\section{Statistical Analysis}

The number of alleles (NA), the observed heterozygosity ( $\mathrm{HO}$ ), and expected heterozygosity (HE) were statistically analyzed using $\mathrm{F}_{\text {stat }}$ version 2.9.3 (Goudet, 2001). The genotypic distributions for conformance to Hardy-Weinberg equilibrium (HWE) and the loci for genotypic linkage dis equilibrium analysis used GENEPOP version 4.0 software. Locus conformance to Hardy-Weinberg equilibrium (HW) and fixation index (FIS) were analyzed using $F_{\text {stat's }}$ statistical genetic software version 2.9.3. (Goudet, 2001). Analysis of molecular variance for knowing temporal and regional comparisons of genetic hetero-geneity among re-

Table 1. Primer sequences and characteristics of five polymorphic microsatellites loci of striped catfish populations

\begin{tabular}{|c|c|c|c|c|}
\hline Locus & Primer sequence (5'-3') & Motif & Range size (bp) & $\operatorname{Tm}\left({ }^{\circ} \mathrm{C}\right)$ \\
\hline $\mathrm{Pg}-1$ & $\begin{array}{l}\text { F : GGCCTGTCACAATGTGTATTGC } \\
\text { R : GTCTGAGGTAGGCCTGTGAGGAG }\end{array}$ & $(\mathrm{CA})_{18}$ & $231-239$ & 64 \\
\hline $\mathrm{Pg}-2$ & $\begin{array}{l}\text { F : TGTGTCTAATCTTGTCCGTGCTG } \\
\text { R : TACTGTTGGACCAGACGTTCCTC }\end{array}$ & $(\mathrm{GA})_{14} \mathrm{~N}_{116}(\mathrm{GT})_{11}$ & $258-276$ & 60 \\
\hline $\mathrm{Pg}-3$ & $\begin{array}{l}\text { F: CCAGCCCACATTAGGTAGCATC } \\
R: \text { ACTAAAAGGCCTGACCCTTAGC }\end{array}$ & $(\mathrm{GT})_{16}$ & $204-220$ & 60 \\
\hline $\mathrm{Pg}-13$ & $\begin{array}{l}\text { F : GTTTTCCATCCAGGTTGTTTTCC } \\
\text { R : TAAGTCCATGTGGGTTTCCTCTG }\end{array}$ & $(\mathrm{CA})_{25}$ & $232-262$ & 58 \\
\hline $\mathrm{Pg}-14$ & $\begin{array}{l}\mathrm{F}: \text { ACCGTGCATGTGCATTATCATAG } \\
\mathrm{R}: \text { AGAATGTGACCTGGAAATGAGCA }\end{array}$ & $\begin{array}{c}(\mathrm{GT})_{5} \mathrm{AT}(\mathrm{GT})_{11} \\
\mathrm{AT}(\mathrm{GT})_{13}\end{array}$ & $289-293$ & 60 \\
\hline
\end{tabular}


gions were conducted using Arlequin 3.5 (Excoffier et al., 2006). An exact test of population differentiation of pairwise weighted mean FST was performed using Arlequin 3.5. A neighborhood joining dendrogram was constructed based on Nei's distance (Da) matrix by carrying out 1,000 bootstrap replications using MEGA7 (Kumar et al., 2016) to determine the genetic relationships among populations.

\section{RESULTS AND DISCUSSION}

The present study showed that 31.5 alleles from five microsatelite loci in the four generations, and the number of allel per locus ranged of 4-7 (Table 2). The genetic variability level of generation populations gradually decreased, while the value of $F_{15}$ gradually increased, reaching a maximum value in the G-2 generation (0.405). It indicated that lost variability and structure of genetic in the next generation.

The genetic performance in each generation of striped catfish populations was determined by observed heterozygosity values and expectation heterozygosity ( $\mathrm{Ho}$ and $\mathrm{He}$ ). Lost of genetic variability has occured in the G-1 and G-2 generations through selective breeding. Based on value of $\mathrm{Ho}$ and $\mathrm{He}$, inbreeding depression have been occured in four generation. The average observed heterozygosity ( $\mathrm{Ho})$ was less than the expectation heterozygosity $(\mathrm{He})$ under the Hardy-Weinberg equilibrium condition $(P<0.05)$. This condition was commonly called the heterozygote deficit and it most probably caused by inbreeding depression. In addition, $F_{\text {is }}$ value indicates the inbreeding degree in a population. Its value ranges from -1 to 1 , and a higher value indicates inbreeding within a population (Weir \& Cockerham, 1984).

The study found that $F_{\text {Is }}$ values was increased successively per generations, indicating inbreeding occured in subsequent generations. Furthermore, heterozygote deficit in the population also increased (Valles-jimenez et al., 2004).
Observed allele frequencies of microsatellite loci for five generations showed that the allele frequencies of most loci fluctuated in different generations. It indicated random variations of allele frequencies in the breeding process. There were some exclusions, such as the allele of the loci Pg-2- $194 \mathrm{bp}, \mathrm{Pg}-13-$ $227 \mathrm{bp}, \mathrm{Pg}-13-229 \mathrm{bp}$, and Pg-14-279 bp; their gene frequencies were increased with breeding (Table 3 ).

The study have indicated that genetic correlations may exist between these (four loci and four alleles) and it has correlated to breeding traits. It was assumed that alleles of this locus related to growth in striped catfish. However, to confirm this relationship, further association analysis studies between traits are necessary. Luo et al. (2015), reported that selection in breeding program causes genes in populations to become homozygous; the affected genes are typically associated with a trait of fish species.

The analysis of molecular variance indicated that most genetic variations arise from individuals within populations (approximately $57.10 \%$, while variation among populations accounted for only $13.61 \%$ (Table 4).

The largest genetic distance was detected from the $\mathrm{G}-0$ to $\mathrm{G}-1$ generations the value is 0.209 , while the lowest genetic distance was detected between the G-1 and G-2 generations the value is 0.031 (Table 5 , Figure 1). The data of genetic distance indicated that selection activity had significant impact on the genetic performance of the breeding populations.

As shown on the clustering map, the founder generation closely related to $\mathrm{G}-0$ generation whereas G-1 generation closely related to G-2 generation (Figure 1). In this case, we suggested that selection program in this study affected to the genetic performance of striped catfish that influenced its genetic distance. Microsatellite genotypes are particularly helpful to detect structure in closely related popula-

Table 2. Average genetic variability of the five microsatellite loci in each selective breeding generation

\begin{tabular}{lccccc}
\hline & Founder & \multicolumn{1}{c}{ G-0 } & \multicolumn{1}{c}{ G-1 } & G-2 & Mean \\
\hline Sample size & 50 & 50 & 50 & 50 & 200 \\
Total $\mathrm{N}_{\mathrm{A}}$ & 26 & 26 & 25 & 25 & 31.5 \\
${\text { Mean } \mathrm{N}_{\mathrm{A}}}_{\mathrm{F}_{\mathrm{IS}}}^{5.0}$ & 5.2 & 5.0 & 5.0 & 5.1 \\
$\mathrm{H}_{\mathrm{e}}$ & 0.29 & 0.35 & 0.36 & 0.41 & 0.4 \\
$\mathrm{H}_{0}$ & 0.69 & 0.69 & 0.7 & 0.7 & 2.8 \\
PIC & 0.49 & 0.49 & 0.51 & 0.42 & 1.9 \\
\hline
\end{tabular}


Table 3. Allele frequencies of loci Pg-13 and Pg-14

\begin{tabular}{cccccc}
\hline \multicolumn{1}{c}{ Alleles } & Founder & G-0 & G-1 & G-2 & Mean \\
\hline Pg-3-194 bp & 0.175 & 0.37 & 0.5 & 0.61 & 0.41 \\
Pg-13-227 bp & 0.125 & 0.175 & 0.187 & 0.34 & 0.21 \\
Pg-13-229 bp & 0.20 & 0.25 & 0.46 & 0.49 & 0.35 \\
Pg-14-279 bp & 0.025 & 0.05 & 0.26 & 0.38 & 0.18 \\
\hline
\end{tabular}

Table 4. Analysis of molecular variance (AMOVA) of five generations

\begin{tabular}{ccccc}
\hline \multicolumn{1}{c}{ Source of variation } & $\mathbf{d b}$ & $\begin{array}{c}\text { Sum of } \\
\text { squares }\end{array}$ & $\begin{array}{c}\text { Variance } \\
\text { components }\end{array}$ & $\begin{array}{c}\text { Percentage of } \\
\text { variation }\end{array}$ \\
\hline Among populations & 3 & 55.108 & 0.27718 & 13.61 \\
Among individuals within populations & 116 & 273.162 & 0.59617 & 29.28 \\
Within populations & 120 & 139.5 & 1.1625 & 57.1 \\
\hline \multicolumn{1}{c}{ Total } & 239 & 467.771 & 2.03585 & \\
\hline
\end{tabular}

Table 5. Genetic distance between four generations of striped catfish populations

\begin{tabular}{lcccc}
\hline \multicolumn{1}{c}{ Population } & Founder & G-0 & G-1 & G-2 \\
\hline Founder & $*$ & & & \\
G-0 & 0.032 & $*$ & & \\
G-1 & 0.196 & 0.209 & $*$ & $*$ \\
G-2 & 0.188 & 0.196 & 0.031 & $*$ \\
\hline
\end{tabular}

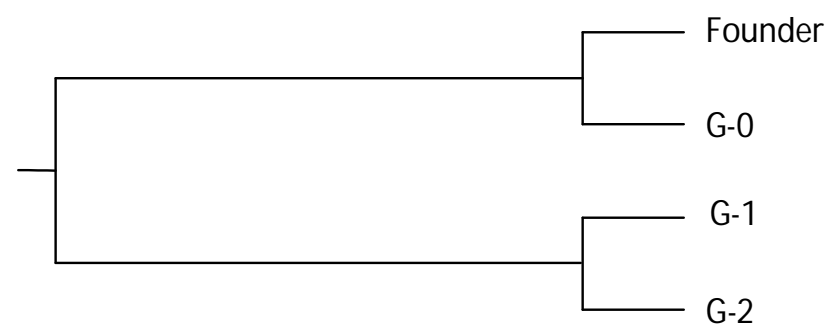

Figure 1. Dendrogram of genetic distances using the UPGM A between four generations of striped catfish populations (the numbers in figure represent branch length).

tions. Genetic distances was influenced by differences in the microsatellite allelic composition of each populations (Chistiakov et al., 2006).

\section{CONCLUSION}

The inbreeding depression have been occured in four generation. Lost of genetic variability has occured in the G-1 and G-2 generations through selective breeding. Most genetic variations arise from individuals within populations (approximately $57.10 \%$. The genetic distance between adjacent generations were increased over successive selection generations from $0.031-0.209$. The founder generation closely related to G-0 generation. Likewise, G-1 generation closely related to $\mathrm{G}-2$ generation. This result indicated that selection activity had a very significant 
impact on the genetic structure of the breeding population.

\section{ACKNOWLEDGEMENTS}

Authors would like to thank technical staff of striped catfish Research Group for providing assistance during the course of the research. This Research was part of works on selective breeding for African catfish growth, funded by Ministry of Marine Affairs and Fisheries.

\section{REFERENCES}

Chistiakov, D.A., Hellemans, B., \& Volckaert, F.A.M. (2006). Microsatellites and their genomic distribution, evolution, function and applications: A review with special reference to fish genetics. Aquaculture, 255, 1-29.

Campbell, D., Duchesne, P., \& Bernatchez, L. (2003). AFLP utility for population assignment studies: analytical investigation and empirical comparison with microsatellites. Molecular Ecology, 12, 19791991.

DeWoody, J.A. \& Avise, J.C. (2000). Microsatellite variation in marine, freshwater and anadromous fishes compared with other animals. Journal of Fish Biology, 56, 461-473.

Excoffier, L., Laval, G., \& Schneider, S. (2006). Arlequin ver. 3.0: An integrated software package for population genetics data analysis. Evolutionary Bioinformatics Online, 1, 47-50.

Gjedrem, T., Robinson, N., \& Rye, M. (2012). The importance of selective breeding in aquaculture to meet future demands for animal protein: A review Aquaculture, 350-353, 117-129.

Goudet, J. (2001). FSTAT, A Program to estimate and test gene diversities and fixation indices, version 2.9.3. Available from http://www.unil.ch/izea/ softwares/fstat.html.

Kumar, S., Stecher, G., \& Tamura, K. (2016). MEGA7: Molecular evolutionary genetics analysis version 7.0 for bigger datasets. M olecular Biology and Evolution, 33, 1870-1874.
Luikart, G., England, P.R., Tallmon, D., Jordan, S., \& Taberlet, P. (2003). The power and promise of population genomics: from genotyping to genome typing. Nature Reviews Genetics, 4, 981-994.

Luo, X.N., Yang, M., Liang, X.F., Jin, K., LV, L.Y., Tian, C.X., Yuan, Y.C., \& Sun, J. (2015). Genetic diversity and genetic structure of consecutive breeding generations of golden mandarin fish (Siniperca scherzeri Steindachner) using microsatellite markers. Genetic and Molecular Research, 14(3), 134811355.

Na-Nakorn, U. \& Moeikum, T. (2009). Genetic diversity of domesticated stocks of striped catfish, Pangasianodon hypophthalmus (Sauvage 1878) in Thailand: Relevance to broodstock management regimes. Aquaculture, 297, 70-77.

Na-Nakorn, U., Sriphairoj, K., Sukmanomon, S., Poompuang, S., \& Kamonrat, W. (2006). Polymorphic microsatellite from DNA of the endangered Mekong giant catfish, Pangasianodon gigas (Chevey) and cross-species amplification in three species of Pangasius. Molecular Ecology Notes, 6, 1174-1176.

Sun, L.F., Li, J., Liang, X.F., Fang, L., Sun, J., He, Y.H., Luo, X.N., Dou, Y.Q., \& Yang, M. (2015). Microsatellite DNA markers and their correlation with growth traits in mandarin fish (Siniperca chuatsi). Genetic and Molecular Reserach, 14(4), 19128-19135.

Valles-jimenez, R., Cruz, P., \& Perez-Enriquez, R. (2004). Population genetic structure of Pacific white shrimp (Litopenaeus vannamei) from Mexico to Panama: microsatellite DNA variation. Marine Biotechnology, 6, 475-484.

Weir, B.S. \& Cockerham, C.C. (1984). Estimating Fstatistics for the analysis of population structure. Evolution, 38, 1358-1370.

Yu, Z.F., Yan, X.W., Yang, F., \& Wang, J.H. (2011). Genetic diversity of different generations of the Dalian population of Manila clam Ruditapes philippinarum through selective breeding. Acta Ecol. Sin., 31, 4199-4206. 